\title{
PRELIMINARY INVESTIGATION OF BILLET PROCESSING ROUTE ON MICROSTRUCTURE, TEXTURE AND FATIGUE RESPONSE OF Ti834 FORGED DISC PRODUCTS
}

\author{
B. Fernandez-Silva ${ }^{1}$, B. P. Wynne ${ }^{1}$, M. Jackson ${ }^{1}$, M. Bodie ${ }^{2}$, K. Fox ${ }^{3}$ \\ ${ }^{1}$ Department of Material Science and Engineering, The University of Sheffield, Sheffield S1 3JD, UK \\ ${ }^{2}$ TIMET UK Limited, P.O. Box 704 Witton, Birmingham B6 7UR, UK \\ ${ }^{3}$ Rolls-Royce plc, P.O. Box 31, Derby DE24 8BJ, UK
}

Keywords: Ti834, texture, macrozones, dwell fatigue, facet

\begin{abstract}
$\underline{\text { Abstract }}$
Non-standard processing routes for the manufacture of industrial scale Ti834 billet have been undertaken to investigate their effect on macrozones in final forged product. Microstructure, texture and dwell fatigue fracture surfaces were characterised from forged disc samples fabricated from these new billets. All processing routes showed a bimodal microstructure consisting of 25 pct of primary alpha grains in a transformed beta matrix. Texture analysis has revealed variations in the presence and size of macrozones with relatively weak textures. Quasi-cleavage facets were present in all dwell fatigue samples although the fatigue life was doubled for the sample whose thermomechanical processing has the highest imposed strain.
\end{abstract}

\section{Introduction}

Near- $\alpha$ titanium alloys have their main application in rotating compressor discs in the high-pressure section of jet turbine engines where a balance of good fatigue and creep properties at high temperatures is required [1]. At the industrial scale these properties can currently only be achieved by thermomechanical processing e.g. via forging. However, the narrow process window of near- $\alpha$ titanium alloys together with the anisotropic behavior of the hexagonal closed packed crystal structure of the $\alpha$-phase makes the final microstructure and crystallographic texture strongly dependent
on temperature and strain path experienced during processing $[2,3]$. Therefore, the selection of process parameters and their careful control is critical to obtain the desired properties.

Ti834 is the most developed near- $\alpha$ titanium alloy for high temperature applications with a temperature capability up to $600^{\circ} \mathrm{C}$. Its excellent fatigue and creep performance capability comes from a bimodal microstructure consisting of primary alpha grains $(\alpha p)$ and secondary alpha colonies ( $\alpha$ s). The development of this microstructure consists of several steps within two processing stages: 1 . primary forging to convert ingot to billet using open die forging and 2 . secondary forging using closed dies to produce a near-net shape final component. In primary forging the first step is above the beta transus $(\mathrm{T} \beta)$ temperature to break down the as-cast microstructure of large $\beta$-grains. This is followed by sub T $\beta$ deformation and a heat treatment to promote recrystallization to reduce $\beta$-grain size, which upon cooling produces a microstructure consisting of $\alpha$ s, whose size is directly impacted by the parent $\beta$-grain size. A further sub T $\beta$ deformation and heat treatment follows to promote dynamic and static spherodization of the $\alpha$ lamellae producing a microstructure of equiaxed $\alpha p$ grains in a matrix of $\alpha$ s. The cooling rate in this last stage defines the volume fraction of $\alpha$ in the billet microstructure and the $\beta$ transforms to $\alpha$ s according to the Burgers orientation relationship. The secondary forging, takes place only sub T $\beta$, aiming to get the near final shape and the optimum volume fraction of $\alpha$ g grains required for the component's application.

Despite the extensive control during processing, microstructure and texture heterogeneities are unavoidable during primary forging and they persist with further processing [7,12] leading to heterogeneous properties within the final components [11]. Electron Backscattered Diffraction (EBSD) observations have shown that local regions within the bimodal microstructure can have similarly oriented $\alpha$ grains [4]. These micro-textured regions are known as macrozones and they are thought to lead to a reduction in fatigue life when the material is exposed to relatively high constant stress during the loading cycle, referred to as dwell fatigue [5,6]. A typical dwell fatigue failure is characterized by a subsurface crack initiation creating quasi-cleavage facets. These facets have been shown to have basal grains perpendicular or near perpendicular to the loading direction $[8,9]$. When regions in the microstructure share similar unfavorably orientation, they can become an easy path for a crack to grow [10]. Therefore, the absolute properties of the final component are not just a result of the last stages of secondary forging but are also heavily dependent on
microstructural features inherited from the primary forging process $[5,10]$.

In this work, samples from Ti834 compressor discs from non-standard billet conversions are under investigation. Microstructure, texture and fracture surfaces of dwell fatigue tested samples are analyzed to establish a relationship between the conversion route, texture formation and its effect in dwell fatigue life.

\section{$\underline{\text { Materials and Methods }}$} The microstructure and texture variation of three differently processed Ti834 compressor discs is studied in this work in relation to its fatigue life and the presence of macrozones. The
thermomechanical processing for compressor disc manufacture involves primary and secondary forging stages. For this work, the primary forging for billet conversion was done by TIMET UK where the new alternative processing routes aimed to control macrozone formation. The secondary forging for compressor disc manufacture was undertaken using standard procedures in all cases with no modifications.

Three full scale production size billets were manufactured from an initial large VAR ingot. The processing route of the billets either varied in total level of deformation producing either 250 or $200 \mathrm{~mm}$ final diameter or temperature at which the material was forged. The samples will be identified depending on their representative processing sizes and temperatures as shown in Table I. Billets are cut in smaller sections for their compression parallel to the long axis of the billet in secondary forging. Throughout all the thermomechanical processing all billets were marked from the processing routes.

Table I Abreviations of samples according to the billet size and processing temperature

\begin{tabular}{ccc}
\hline Abbreviation & Billet size $(\mathrm{mm})$ & Temperature* \\
\hline $250 \mathrm{TT}$ & 250 & $\mathrm{TT}$ \\
$250 \mathrm{~T}$ & 250 & $\mathrm{~T}$ \\
$200 \mathrm{~T}$ & 200 & $\mathrm{~T}$ \\
\hline \multicolumn{3}{c}{}
\end{tabular}

Dwell fatigue testing was undertaken on cylindrical tensile specimens using a trapezoidal waveform 1-60-1-1 seconds at $80^{\circ} \mathrm{C}$ with a maximum and minimum applied stress of $815 \mathrm{MPa}$ and $40 \mathrm{MPa}$ until failure. Fracture surfaces of dwell fatigue tested samples were observed by SEM at low voltage $(5 \mathrm{kV})$ for facets identification. Further sample preparation was undertaken on dwell fatigue until failure. Fracture surfaces of dwell fatigue tested samples were observed by SEM at low voltage (5kV) for facets ident
tested samples for texture analysis on the cross section perpendicular to the fracture surface, just below crack initiation point.

For microstructure and texture analysis compressor disc samples were machined, mounted in bakelite and polished for both the axial (AD) and one radial direction (RD) of the billet/compressor disc. To reveal the microstructure, samples were etched using Krolls reagent for 15 seconds. At least five micrographs were taken by optical microscopy to obtain the grain size, aspect ratio and volume fraction of primary alpha grains. Volume fraction was obtained automatically by a script developed in Matlab applying a threshold as a function of primary alpha grains size and shape. Grain size was measured with the linear intercept method for bimodal microstructures. Orientation data was obtained with a QUANTA FEG 250 SEM using AZTEC software for data acquisition and HKL Channel 5 for post-processing analysis.

\section{$\underline{\text { Results }}$}

Microstructure

Representative micrographs from all three processing routes show a bimodal microstructure on the final component with primary alpha grains ( $\alpha$ p) and secondary alpha colonies ( $\alpha$ s), Figure 1. The results from the microstructural analysis are covered in Table II. The $\alpha$ volume fraction for this component aims to be around $25 \%$, in this case slightly variations with values of 22,24 and $27 \%$ results from the microstructural analysis are covered in Table 1 . The $\alpha$ p volume fraction for this component aims to be around $25 \%$, in this case slightly $\mathrm{v}$.
respectively with an average $\alpha$ grain size around $20 \mu \mathrm{m}$. Grain boundary alpha $(\alpha \mathrm{GB})$ is present in all three samples defining the prior beta grain boundaries.

The $\alpha$ prain size distributions are displayed in Figure 2a and show a normal distribution with an average $\alpha$ prain size that decreases with increasing billet size and processing temperature. The coarser and more equiaxed microstructure belongs to the compressor disc sample fabricated from the smaller billet diameter (200T). For samples from the larger billet-diameters, $\alpha \mathrm{p}$ particles are slightly more elongated showing a preferential deformation near 45 degrees from the forging direction. Although sample $250 \mathrm{~T}$ has the smaller grains size, it seems to create agglomerates of $\alpha \mathrm{p}$ grains and the same tendency is followed by sample 200T. An assessment on the agglomeration tendency was done on each sample. The number of neighbours per sample was calculated according

(C) The Authors, published by EDP Sciences. This is an open access article distributed under the terms of the Creative Commons Attribution License 4.0 (http://creativecommons.org/licenses/by/4.0/). 
to the number of $\alpha$ grains that are near a given grain. For each sample random $\alpha$ p grains were selected and the number of neighbouring $\alpha p$ grains were counted within a circular area of $100 \mu \mathrm{m}$ radius. Results in Figure $2 b$ display the $\alpha$ p grain clustering tendency for each sample.
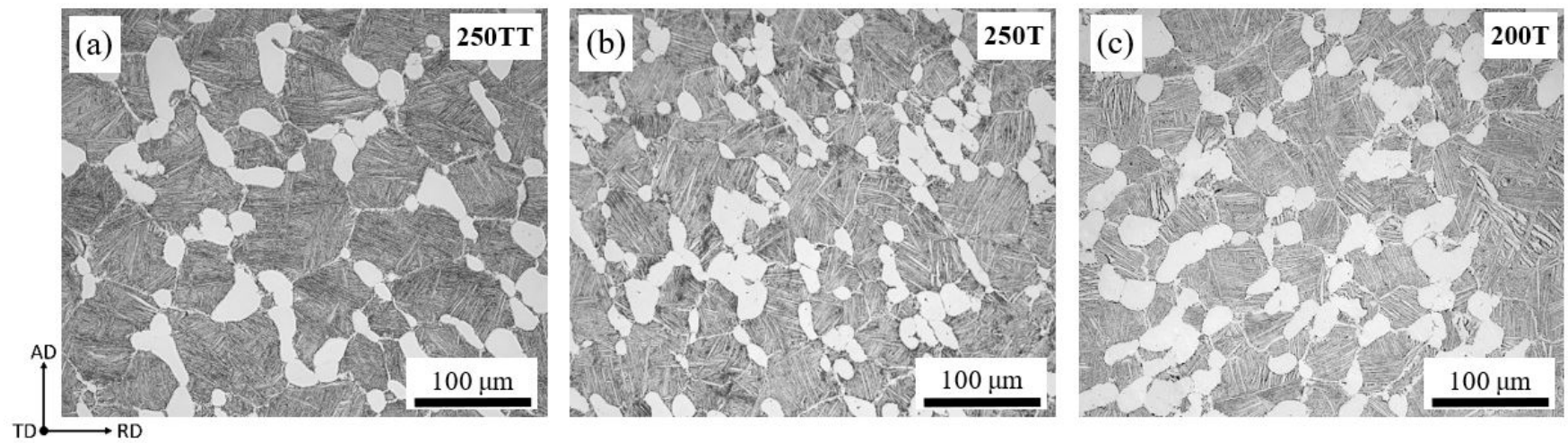

Figure 1 Optical micrograph of Ti834 from compressor discs samples from billets 250TT (a), 250T (b) and 200T (c). Forging direction in the vertical axis.

Table II Microstructure analysis results of primary alpha grains

\begin{tabular}{lcccc}
\hline Material & Grain Size $(\mu \mathrm{m})$ & Volume fraction & Aspect ratio & Number of neighbours \\
\hline $250 \mathrm{TT}$ & $19.8 \pm 0.5$ & 22 & $1: 2.6$ & $12.8 \pm 0.5$ \\
$250 \mathrm{~T}$ & $17.6 \pm 0.4$ & 24 & $1: 3$ & $20.3 \pm 0.6$ \\
$200 \mathrm{~T}$ & $22.8 \pm 0.5$ & 27 & $1: 1.8$ & $14.9 \pm 0.4$ \\
\hline
\end{tabular}
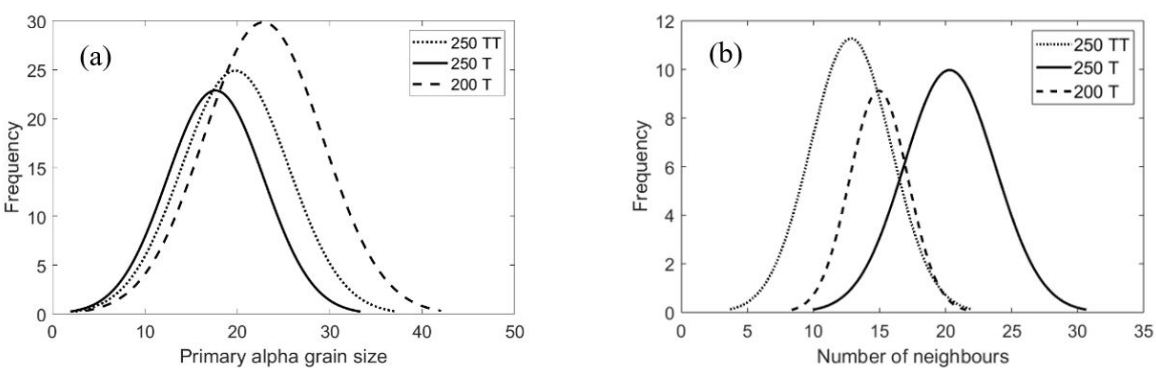

Figure 2 (a) Grain size and (b) number of neighbouring grains distribution

Texture

Only alpha phase was considered for texture analysis, since the $\beta$-phase amount in this alloy for the current application is around 4-6 \%. The orientation maps obtained by EBSD scans covering areas of $5 \times 2 \mathrm{~mm}$ with $5 \mu \mathrm{m}$ step size are displayed in Figure 3. In this case, the axial direction of the billet matching the horizontal axis. The degree of texture was relatively weak for all cases: 2.2 $\mathrm{mrd}$ for $250 \mathrm{TT}$ and 200T, and have the basal plane perpendicular the transverse direction (TD). Samples 250TT and 200T show a relatively presence of some basal orientated clusters with similar deformation tendency as it was present in the microstructure. These strong texture regions are not present in samples from 250TT and 200T. The strength is highlighted for the samples with larger diameter, while characterized as low density macrozones of approximately $1 \mathrm{~mm}$ in length by $0.5 \mathrm{~mm}$ wide.
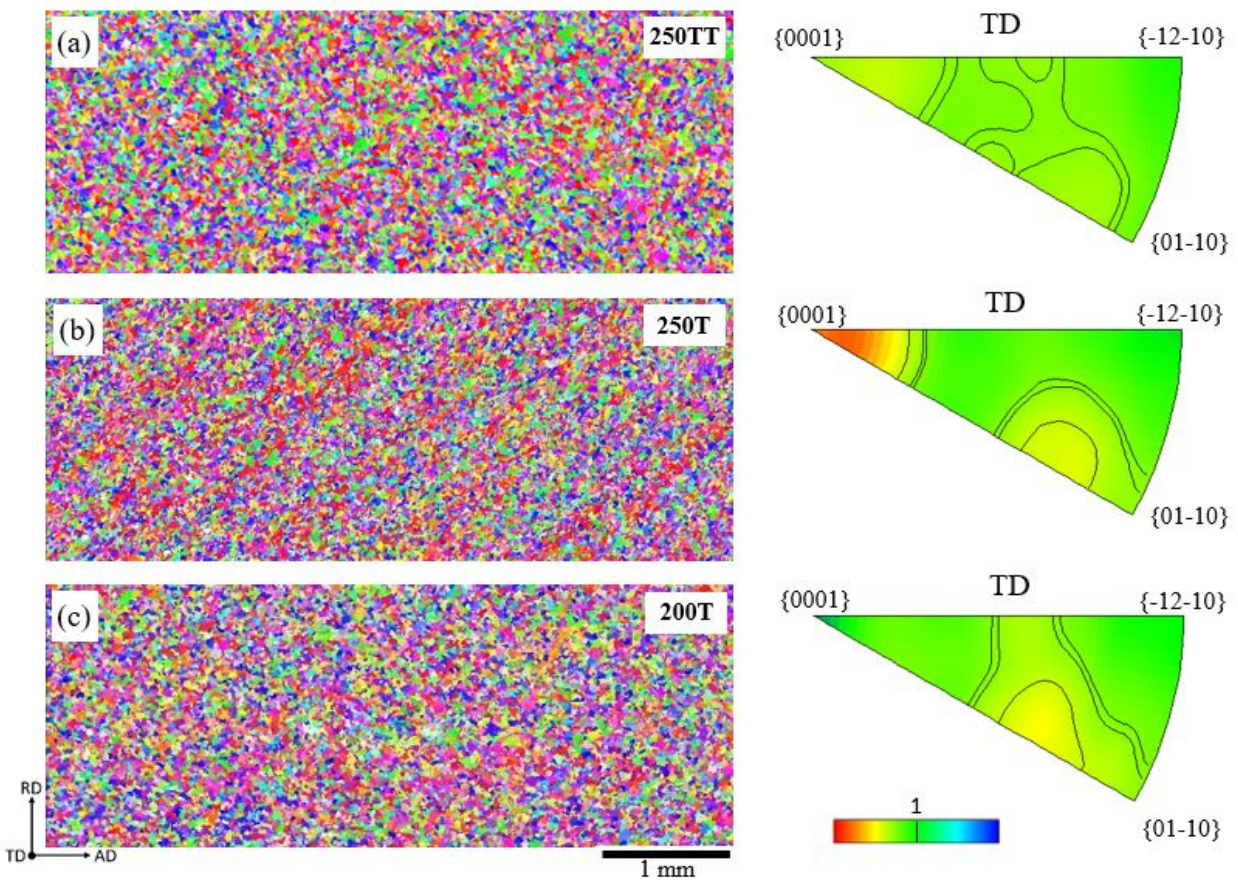

Figure 3 Orientation map in the IPF colouring of compressor disc samples from same location and Inverse Pole Figures referred to TD direction from 250TT (a), 250T (b) and 200T (c) billet conversion
routes. Forging direction is on the horizontal axis.

Dwell Fatigue

Dwell fatigue results are summarised in Table III. Note that for this isolated test, samples were taken from the same position of each disc; fatigue life of samples taken from different positions of the compressor disc may vary slightly. The fatigue sample taken from the smallest billet-diameter has shown the best dwell fatigue performance, by almost doubling the fatigue life to failure.

Table III Dwell fatigue results using trapezoidal waveform 1-60-1-1 at $815 \mathrm{MPa} / 80^{\circ} \mathrm{C}$

\begin{tabular}{lccc}
\hline Billet & $250 \mathrm{TT}$ & $250 \mathrm{~T}$ & $200 \mathrm{~T}$ \\
Cycles to failure & 3930 & 4292 & 7092 \\
\hline
\end{tabular}

High-resolution SEM imaging shows differences in the fracture surface in Figure 4. Samples with large-diameter size (250TT and 250T) display the typical quasi-cleavage facets of dwell fatigue failure. Clusters of primary alpha grain sharing the same crystal orientation usually create facets. Such tendency for facet nucleation is not as clear for the smaller diameter sample (200T), where micro voids are noticed as the main feature on the fracture surface. The main facet in samples 250TT and 250T have sizes of $1 \mathrm{~mm}$ wide and are located on the centre and side of the samples respectively, matching with the crack initiation point. These faceted initiation sites are highlighted with dotted circles on the fracture surface.

(a) $250 \mathrm{TT}$

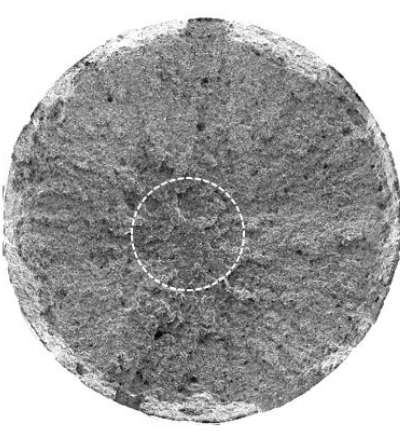

(b) $250 \mathrm{~T}$

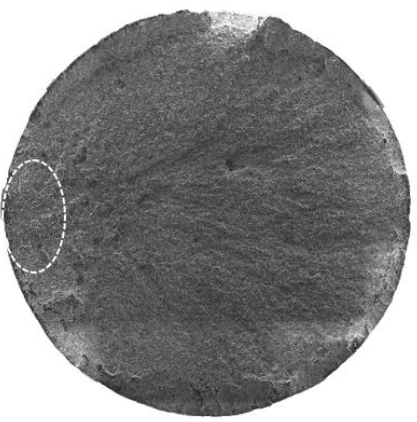

(c) $200 \mathrm{~T}$

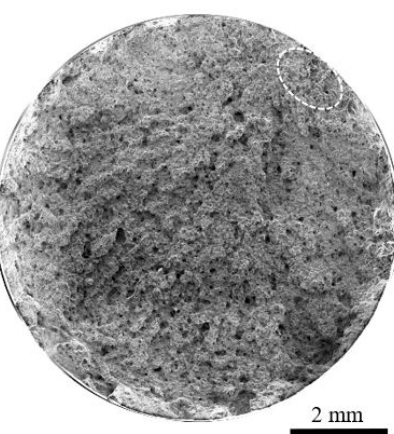

Figure 4 Dwell fatigue fracture surface showing quasi-cleavage facets on compressor disc samples from 250TT (a), 250T (b) and 200T(c) billet conversion route.

Subsurface cracks were visible on the cross-section of each fracture surface in Figure 5. These cracks are mainly present in primary alpha grains with near hard orientation, parallel or slightly inclined from the fracture surface. Isolated cracks were also found in as colonies. Orientation analysis was done on the cross section just below the fracture surface on several grains with cracks. Figure 5 displays the EBSD analysis and the backscattered image from the same location. High-resolution EBSD with $1 \mu \mathrm{m}$ step size revealed the near basal nature of the $\alpha$ p grains showing cracks. The microstructure and orientation analysis have showed that the number of basal oriented grains below the fracture surfaces are reduced with decreasing billet size.
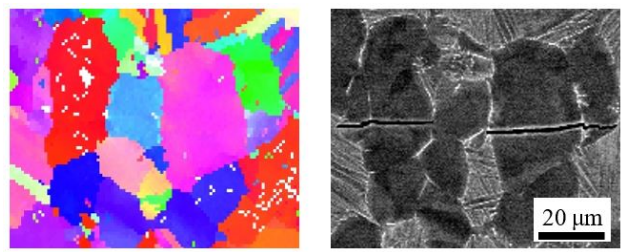

Figure 5 Orientation map in IPF colouring coded according the dwell fatigue load direction and BSE image displaying cracks in $\alpha_{p}$ grains.

Dwell fatigue, texture and macrozones It is important to notice that the direction of the load applied during dwell fatigue testing is parallel to the TD direction of the samples analysed here. This means that the red grains with basal
orientation in Figure 5 have their c-axis aligned with the load direction, i.e.: the basal (0001) plane perpendicular to the load. As previously mentioned in the introduction, this is the worst-case scenario for facet formation. Clusters of basal oriented grains were only observed in sample 250T. The average size of these clusters is approximately $1 \mathrm{~mm}$ wide, similar to the facet size on the scenario for facet formation. Clusters of basal oriented grains were only observed in sample $250 \mathrm{~T}$. The average size of these clusters is approximately $1 \mathrm{~mm}$ wide, similar to the facet size on the
fracture surface of the same sample. This would indicate a direct relation between cluster sharing same basal orientation and facet formation. Nevertheless, the sample $250 \mathrm{TT}$ have also shown a short fatigue life with the presence of quasi-cleavage facets but has not shown any preference for cluster formation.

\section{Discussion}

Variations in texture and fatigue life of Ti834 compressor disc samples from different billet conversion routes were observed in this investigation. As was expected, the volume fraction of ap grains at the processing temperatures used is very similar for all three compressor discs. The smaller billet diameter is assumed to have higher imposed strain as more passes are required to reduce the billet size and increased mechanical work required to fill the die during closed die forging for compressor disc manufacture. The $250 \mathrm{TT}$ billet has a slightly coarser microstructure with a lower tendency for ap grains agglomeration than the other two samples studied here. The $200 \mathrm{~T}$ billet has a slightly higher volume fraction of primary alpha with a minor tendency of agglomeration, a more random texture of this sample, and an increase in the dwell fatigue life. In comparison with sample 250TT and sample 250T, the fatigue life was increased by factors of 1.8 and 1.6 respectively. However, samples from other locations within the compressor disc not analysed here have shown a less clear trend. This may be a result of heterogeneity induced by the primary forging process around the billet that remains on the final component [13].

Despite the overall weak texture, high aspect ratio and similarly orientated clusters were present in sample 250T. A higher density of basal orientated grains was found in samples from the larger diameter billets. Fatigue life improves with reducing billet size and processing temperature. Samples with shorter fatigue life display quasi-cleavage facets. The lack of facets on the sample $200 \mathrm{~T}$ can be linked to the absence of basal orientated grains, which together with the presence of micro voids indicated a more ductile fracture than the others. Although no major changes were observed on the fatigue behaviour and fracture surface of the 250 -millimetre billets, clear differences are displayed on the orientation maps as sample $250 \mathrm{~T}$
displays macrozones that are not present on the $250 \mathrm{TT}$ as the Inverse Pole Figures feature the presence of basal grains aligned with the TD direction. The presence of macrozones has not been mentioned for sample 250TT although the small area measured during EBSD analysis could be the cause for this as the fracture surface indicates that a major facet has acted as the crack initiation point for the failure on this sample. The size of the quasi-cleavage facet on sample 250T is equivalent to the macrozone size observed on its orientation map.

\section{Conclusion}

Three alternative processing routes have been assessed in terms of microstructure, texture and dwell fatigue life of Ti834 compressor disc alloy. The routes have demonstrated the ability to reduce macrozone size by optimising billet manufacturing routes. The sample from the compressor disc manufactured from the smaller billet diameter has shown the best fatigue life. Differences in properties of the final component.

\section{Acknowledgements}


This research is funded by Rolls-Royce and the EPSRC grant EP/L016273 Centre for Doctoral Training in Advanced Metallic Systems. The author gratefully acknowledges the provision of SEM facilities of TIMET UK and assistance during the EBSD analysis for the texture data shown in this project.

\section{$\underline{\text { References }}$}

[1] Peters, M., \& Leyens, C. (2003). Titanium and Titanium Alloys.

[2] Flower, H. M. (1990). Microstructural development in relation to hot working of titanium alloys. Materials Science and Technology.

[3] Lutjering, G. (1998). Influence of processing on microstructure and mechanical properties of $(\alpha+\beta)$ titanium alloys. Materials Science and Engineering A, 243(1-2), 32-45

[4] Bache, M. R. (2003). A review of dwell sensitive fatigue in titanium alloys: The role of microstructure, texture and operating conditions. International Journal of Fatigue, 25(9-11), 1079-1087.

[5] Le Biavant K., Pommier S., Prioul, C.: Local texture and fatigue crack initiation in a Ti-6Al-4V titanium alloy, Fatigue and Fracture of Engineering Materials and Structures, 2002, 25(6), 527545.

[6] Bache M., Cope M., Davies H., Evans W., Harrison, G.: Dwell sensitive fatigue in a near alpha titanium alloy at ambient temperature, International Journal of Fatigue, 1997, 19(93), 83-88.

[7] Wanjara, P., Jahazi, M., Monajati, H., Yue, S., \& Immarigeon, J. P. (2005). Hot working behavior of near- $\alpha$ alloy IMI834. Materials Science and Engineering A.

[8] Sinha, V., Spowart, J. E., Mills, M. J., \& Williams, J. C. (2006). Observations on the faceted initiation site in the dwell-fatigue tested Ti-6242 alloy: Crystallographic orientation and size effects. Metallurgical and Materials Transactions A: Physical Metallurgy and Materials Science, 37(5), 1507-1518.

[9] Pilchak, A. L., \& Williams, J. C. (2011). Observations of facet formation in near- $\alpha$ titanium and comments on the role of hydrogen. Metallurgical and Materials Transactions A: Physical Metallurgy and Materials Science, 42(4), 1000-1027.

[10] Zhang, K., Yang, K. V., Lim, S., Wu, X., \& Davies, C. H. J. (2017). Effect of the presence of macrozones on short crack propagation in forged two-phase titanium alloys. International Journal of Fatigue, 104, 1-11

[11] Gey, N., Bocher, P., Uta, E., Germain, L., \& Humbert, M. (2012). Texture and microtexture variations in a near- $\alpha$ titanium forged disk of bimodal microstructure. Acta Materialia.

[12] Pilchak, A. L., Szczepanski, C. J., Shaffer, J. A., Salem, A. A., \& Semiatin, S. L. (2013). Characterization of microstructure, texture, and microtexture in near-alpha titanium mill products. In Metallurgical and Materials Transactions, A: Physical Metallurgy and Materials Science.

[13] Wilson, A.F., Venkatesh, V., Pather, R., Brooks, J.W., Fox, S.P. The prediction of microstructural development during TIMETAL 64 billet manufacture. In Proceedings of the 10th world conference on titanium, Hamburg; 2003. p. 322. 